\title{
Sustainability Assessment Based on Weighing Method of Combined Subjective-objective -Case of Shaanxi Province in Northwestern China
}

\author{
Shengting $\mathrm{LI}^{1 \text { st }}$, Xiaowei $\mathrm{ZHOU}^{2 \text { nd }}$ \\ ${ }^{1}$ International Bussiness School of Shaanxi Normal University Xi'an, 710119, China \\ ${ }^{2}$ International Bussiness School of Shaanxi Normal University Xi'an, 710119, China
}

\begin{abstract}
Based on the principle of the triple bottom line (economy, society and environment), considering about energy export region of Shaanxi actual situation, this paper constructed a comprehensive assessment for sustainability of industrial ecosystem (SIE) by weighing method of combined subjective-objective (CSO) and based on the data from 2008 to 2018. The research results indicated that the sustainable development of industrial ecosystem continues to improve and the policy guidance plays a significant role in this process. Many policy measures had characteristic of Shaanxi, such as the strategies of energy industry-- stable production and quality improvement, structural optimization of non-energy industry and the leading role of major project.
\end{abstract}

\section{INTRODUCTION}

After 40 years of rapid economic growth and sufficient accumulation, the contradiction between economic development and the environment has exposed obviously, and policy makers are aware and intend to resolve this crucial contradiction--- pursuing economic growth efficiency to meet the needs of all social members of the society, and maintain the stable and benign evolution of the society within the limits ecological environment permits. The sustainable development has become the value orientation of China's current economic development. As a country with a vast territory, China has uneven economic development and the distribution of natural resources. The ecological environment in the northwest region is particularly fragile, which has a more significant restricting effect on the economy. Therefore, the northwest region of China must treat the environmental restricting effect in a more important position than the eastern region. This paper discussed how to comprehensively and objectively evaluate SIE in a typical area of northwest China, and to apply the concept of sustainable development to the operation and structural adjustment of the industrial system by referring to the evaluation results.

\section{LITERATURE REVIEW}

Industrial ecosystem theory has become a multidisciplinary cross-application research field, involving economics, management, society, network, biological evolution and other disciplines after 30 years of deepening and extension on concept and connotation.
Many scholars conducted abundant researches on industrial ecosystem based on different theories and methods. The study mainly about the evaluation and assessment of the industrial ecosystem, such as assessing the sustainability or efficiency of region1 using case study2, constituting comprehensive evaluation index3, Ecological performance evaluation, vector autoregression model4 and so on. At present, the evaluation of industrial ecosystem focuses on the triple bottom line (social, economic and environment) approach to sustainability 15. Based on the principle of case by case, regions with different resource endowments maybe have different emphases on aspects of sustainable development. For resource-dependent regions, energy sustainability is worthy of attention. Therefore, energy sustainability was included in the scope of investigation of industrial ecosystem sustainability of Shaanxi in this paper.

The evaluation of SIE in previous studies mostly employed the analytic hierarchy process (AHP) method6 or the maximum entropy method(MEM)7. Subjective weighting methods(such as AHP) can clearly express the value judgment of the evaluation subject to the evaluation object, but the results are subjective distinctly, without of considering the difference of the information capacity of the data sample; Objective weighting method(such as MEM) selects the combination of factors with greater entropy based on the information entropy of the sample, but the stability of the results is poor due to the excessive dependence on the sample data8.It can be seen that subjective and objective valuation methods have their own advantages and disadvantages in practical application. Therefore, this paper adopts the weighing method of combined subjective-objective (CSO) in order to organically integrates the results of subjective and 
objective weighting. By doing so, it can gain an advantage from the both two, evaluation weight sequence can reflect both the value orientation of the evaluator and the heterogeneity of sample entropy9.

\section{METHODS}

\subsection{Indicator system}

the United Nations Conference on Sustainable Development proposed change in green economy paradigm_emphasizing the undiminished development of the earth's key natural capital, based on the idea of strong sustainable development, it means that human economic and social development must be limited to the boundaries and natural limits of the earth. Sustainability science is a solution-oriented discipline that studies the complex relationship between nature and humankind, conciliating the scientific and social reference paradigms which are mutually influenced, and covering multi temporal and spatial scales. The discipline implies a holistic approach, able to capitalise and integrate sectorial knowledge as well as a variety of epistemic and normative stances and methodologies towards the definition of solutions 10.

Sustainable development became a cross-cutting concept including three dimensions - social, economic and environment11. In accordance with the concept, sustainability assessment should be one of the most complex types of appraisal activity, as it is multidisciplinary in nature and based on cultural and valuebased elements10.In order to evaluate SIE, it is important to seek the evaluation subject and the stakeholders of the industrial ecosystem, and to clarify their needs and expectations. Only in this way, is it possible to define the connotation involved of the assessment of industrial ecosystem objectively and comprehensively10. The goal of the industrial ecosystem is to coordinate the contradiction between the expansion of the industrial system and the deterioration of the ecological environment, so as to ensure the industrial system in optimum and sustainable status within the reasonable space of environmental constraints. As an energy exchange link between human society and nature, industrial system's operation mode and efficiency will inevitably affect the society, environment and economic system itself, which are the stakeholders of industrial ecosystem system.

Table 1 the assessment system of SIE

\begin{tabular}{|c|c|c|c|c|c|c|c|}
\hline destination & Subsystems & $\begin{array}{c}\text { Secondary } \\
\text { subsystems }\end{array}$ & Indicator (unit) & Attribute & $\begin{array}{c}\text { MEM } \\
\text { weight }\end{array}$ & $\begin{array}{c}\text { AHP } \\
\text { weight }\end{array}$ & $\begin{array}{c}\text { CSO } \\
\text { weight }\end{array}$ \\
\hline \multirow{20}{*}{ SIE } & \multirow[t]{3}{*}{$\begin{array}{l}\text { Energy } \\
\text { sustainability }\end{array}$} & \multirow[t]{2}{*}{$\begin{array}{l}\text { energy } \\
\text { consumption }\end{array}$} & $\begin{array}{l}\text { Energy consumption per unit output value } \\
\text { (10000 Tons of standard coal / } 100 \text { million } \\
\text { yuan) }\end{array}$ & Negative & 0.033 & 0.019 & 0.019 \\
\hline & & & $\begin{array}{l}\text { Water consumption per unit output value } \\
(100 \text { million cubic meters / } 100 \text { million yuan })\end{array}$ & Positive & 0.027 & 0.019 & 0.019 \\
\hline & & Energy efficiency & $\begin{array}{l}\text { Unit energy processing and conversion } \\
\text { efficiency }(\%)\end{array}$ & Positive & 0.039 & 0.038 & 0.039 \\
\hline & \multirow[t]{5}{*}{$\begin{array}{l}\text { Environment } \\
\text { sustainability }\end{array}$} & \multirow[t]{3}{*}{$\begin{array}{l}\text { Environment } \\
\text { quality }\end{array}$} & $\begin{array}{l}\text { The proportion of days with air quality above } \\
\text { grade } 2(\%)\end{array}$ & Positive & 0.055 & 0.118 & 0.055 \\
\hline & & & Total effluent discharge (10000 tons) & Negative & 0.044 & 0.039 & 0.043 \\
\hline & & & $\begin{array}{l}\text { Emissions of industrial sulphur dioxide (Ten } \\
\text { million tons) }\end{array}$ & Negative & 0.081 & 0.039 & 0.081 \\
\hline & & \multirow[t]{2}{*}{$\begin{array}{l}\text { pollution } \\
\text { abatement }\end{array}$} & $\begin{array}{l}\text { Total investment in pollution control (100 } \\
\text { million yuan) }\end{array}$ & Positive & 0.050 & 0.049 & 0.050 \\
\hline & & & $\begin{array}{l}\text { Investment in the treatment of industrial } \\
\text { pollution sources ( } 10 \text { thousand yuan) }\end{array}$ & Positive & 0.043 & 0.016 & 0.016 \\
\hline & \multirow{8}{*}{$\begin{array}{l}\text { Economic } \\
\text { sustainability }\end{array}$} & \multirow{3}{*}{$\begin{array}{l}\text { Economic } \\
\text { efficiency }\end{array}$} & GDP (100 million yuan) & Positive & 0.045 & 0.173 & 0.087 \\
\hline & & & $\begin{array}{l}\text { Added value of secondary industry (100 } \\
\text { million yuan) }\end{array}$ & Positive & 0.041 & 0.058 & 0.047 \\
\hline & & & $\begin{array}{l}\text { Added value of tertiary industry (100 million } \\
\text { yuan) }\end{array}$ & Positive & 0.052 & 0.058 & 0.058 \\
\hline & & \multirow[t]{3}{*}{$\begin{array}{l}\text { innovative } \\
\text { development }\end{array}$} & $\begin{array}{l}\text { Internal expenditure of R\&D funds (10 } \\
\text { thousand yuan) }\end{array}$ & Positive & 0.034 & 0.082 & 0.034 \\
\hline & & & \begin{tabular}{|c|} 
Patent for invention + patent for utility \\
model (item)
\end{tabular} & Positive & 0.050 & 0.041 & 0.044 \\
\hline & & & Technology market turnover (100 million $)$ & Positive & 0.063 & 0.020 & 0.063 \\
\hline & & \multirow[t]{2}{*}{$\begin{array}{l}\text { industrial } \\
\text { transformation }\end{array}$} & $\begin{array}{l}\text { The ratio of coal, oil and natural gas } \\
\text { exploitation to GDP (\%) }\end{array}$ & Negative & 0.047 & 0.018 & 0.018 \\
\hline & & & $\begin{array}{l}\text { GDP contribution rate of high-tech industry } \\
(\%)\end{array}$ & Positive & 0.070 & 0.053 & 0.070 \\
\hline & \multirow{4}{*}{$\begin{array}{l}\text { society } \\
\text { sustainability }\end{array}$} & \multirow[t]{2}{*}{ social benefit } & GDP per capita（ten thousand yuan/person) & Positive & 0.044 & 0.060 & 0.060 \\
\hline & & & Urbanization rate $(\%)$ & Positive & 0.051 & 0.020 & 0.051 \\
\hline & & \multirow[t]{2}{*}{ social stability } & Engel coefficient & Negative & 0.087 & 0.020 & 0.087 \\
\hline & & & unemployment rate $(\%)$ & Negative & 0.044 & 0.060 & 0.060 \\
\hline
\end{tabular}




\subsection{Data and method}

The process is as follows:

1) standardize the data using the range standardization method.

The positive indicator standardization formula:

$$
X_{i j}=\frac{X_{i j}-\min X_{j}}{\max X_{j}-\min X_{j}}
$$

The negative indicator standardization formula:

$$
X_{i j}=\frac{\max _{j}-X_{i j}}{\max X_{j}-\min X_{j}}
$$

Then, the sample matrix composed of $n$ indexes and $k$ evaluation objects is

$$
X=\left(x_{1}, x_{2}, \cdots, x_{k}\right)=\left[\begin{array}{ccc}
x_{11} & \cdots & x_{1 k} \\
\vdots & \ddots & \vdots \\
x_{n 1} & \cdots & x_{n k}
\end{array}\right]_{n \times k}
$$

2) calculate the weight with AHP as $\beta_{1}$ column and with MEM as $\beta_{2}$ column to form the weight matr:

$$
x \theta=\left[\beta_{1}, \beta_{2}\right]=\left[\begin{array}{cc}
\beta_{11} & \beta_{12} \\
\beta_{21} & \beta_{22} \\
\vdots & \vdots \\
\beta_{k 1} & \beta_{k 2}
\end{array}\right]
$$

3) Determine reasonable range of the ith index weight:

$$
\theta_{i}^{-}=\min \left\{\beta_{i 1}, \beta_{i 2}\right\}, \theta_{i}^{+}=\max \left\{\beta_{i 1}, \beta_{i 2}\right\} ;
$$

Take $r$ values from the interval of $\left(\theta_{i}{ }^{-}, \theta_{i}{ }^{+}\right)$ equably (including upper and lower boundary values) to form the prepared weight interval matrix $\mathrm{W}$ :

$$
\begin{aligned}
& \forall \alpha_{i j} \in\left(\theta_{i}^{-}, \theta_{i}^{+}\right), \quad(j=1, \cdots, r) \\
& W=\left(w_{1}, w_{2}, \ldots, w_{r}\right)= \\
& {\left[\begin{array}{cccc}
\alpha_{11} & \alpha_{12} & \ldots & \alpha_{1 r} \\
\alpha_{21} & \alpha_{22} & \ldots & \alpha_{2 r} \\
\vdots & \vdots & \ldots & \vdots \\
\alpha_{n 1} & \alpha_{n 2} & \ldots & \alpha_{n r}
\end{array}\right]}
\end{aligned}
$$

4) comprehensive evaluation result vector $Z$ is:

$$
Z=W^{T} \cdot X=\left[\begin{array}{c}
W_{1}{ }^{T} \\
\vdots \\
w_{r}{ }^{T}
\end{array}\right] \cdot\left(x_{1}, x_{2}, \cdots, x_{k}\right)=
$$

$$
\left[\begin{array}{cccc}
w_{1}{ }^{T} \cdot x_{1} & w_{1}{ }^{T} \cdot x_{2} & \ldots & w_{1}{ }^{T} \cdot x_{k} \\
w_{2}{ }^{T} \cdot x_{1} & w_{2}{ }^{T} \cdot x_{2} & w_{2}{ }^{T} \cdot x_{k} \\
\vdots & \vdots & \vdots \\
w_{r}{ }^{T} \cdot x_{1} & w_{r}{ }^{T} \cdot x_{2} & \ldots & w_{r}{ }^{T} \cdot x_{k}
\end{array}\right]=\left[\begin{array}{c}
Z_{1} \\
\vdots \\
z_{r}
\end{array}\right]=
$$

$\left[\begin{array}{cccc}\sum_{t=1}^{n}\left(\alpha_{t 1} \cdot x_{t 1}\right) & \sum_{t=1}^{n}\left(\alpha_{t 1} \cdot x_{t 2}\right) & \ldots & \sum_{t=1}^{n}\left(\alpha_{t 1} \cdot x_{t k}\right) \\ \sum_{t=1}^{n}\left(\alpha_{t 2} \cdot x_{t 1}\right) & \sum_{t=1}^{n}\left(\alpha_{t 2} \cdot x_{t 2}\right) & \ldots & \sum_{t=1}^{n}\left(\alpha_{t 2} \cdot x_{t k}\right) \\ \vdots & \vdots & \vdots & \vdots \\ \sum_{t=1}^{n}\left(\alpha_{t r} \cdot x_{t 1}\right) & \sum_{i=1}^{n}\left(\alpha_{t r} \cdot x_{t 2}\right) & \ldots & \sum_{t=1}^{n}\left(\alpha_{t r} \cdot x_{t k}\right)\end{array}\right]$

$z_{i}$ is the weight sequence of the index under the ith weight option in the total $r$ weight sequence options, then its mean value

$$
\overline{z_{l}}=\frac{1}{k} \sum_{j=1}^{k} z_{i j}=\frac{1}{k} \sum_{j=1}^{k} \sum_{t=1}^{n}\left(\alpha_{t i} \cdot x_{t j}\right)
$$

5) Get the weight sequence with the largest variance:

$$
\begin{aligned}
& \underset{i=1, \ldots, r}{\max }\left\{\frac{1}{k-1} \sum_{j=1}^{k}\left(z_{i j}-\overline{z_{l}}\right)^{2}\right\} \\
& \text { s.t. }\left\{\begin{array}{c}
\sum_{i=1}^{k} \alpha_{i j}=1 \quad(j=1, \ldots r) \\
\forall \alpha_{i j} \in\left(\theta_{i}^{-}, \theta_{i}^{+}\right),(j=1, \cdots, r)
\end{array}\right.
\end{aligned}
$$

The weights of the indicators can be calculated by following the steps above, not tired in words here. The associated weights were shown in Table1. As can be seen from the above table, CSO weight adjusts and gains the weight sequence with the largest variance in weight sequence of AHP and MEM, the weight result can present the evaluator's tendency to value with consideration to the difference in information entropy, so the results were more stable and reliable.

\section{$4 \quad$ RESULTS AND FINDINGS}

All of data used in this study are collected from the following sources: Shaanxi Statistical yearbook (20082018), China industry statistical yearbook (2008-2018), China statistical yearbook on environment (2008-2018), China statistical yearbook on high technology industry (2008-2018) and China statistical yearbook on science and technology (2008-2018). Putting the normalized indicator values and the associated weights (shown in Table 2) into Equation process, we obtain the sustainability performances of Shaanxi.

Table 2 The sustainability degrees of subsystem and in the year 2008-2018

\begin{tabular}{cccccc}
\hline & $\begin{array}{c}\text { Energy } \\
\text { sustainability }\end{array}$ & $\begin{array}{c}\text { Environment } \\
\text { sustainability }\end{array}$ & $\begin{array}{c}\text { Economic } \\
\text { sustainability }\end{array}$ & $\begin{array}{c}\text { Social } \\
\text { sustainability }\end{array}$ & $\begin{array}{c}\text { Composite } \\
\text { Indexes }\end{array}$ \\
\hline 2008 & 0.0001 & 0.0601 & 0.0377 & 0.0049 & 0.1028 \\
2009 & 0.0104 & 0.0797 & 0.0411 & 0.0052 & 0.1363 \\
2010 & 0.0216 & 0.1073 & 0.0919 & 0.0268 & 0.2476 \\
2011 & 0.0383 & 0.0803 & 0.0921 & 0.0648 & 0.2755 \\
2012 & 0.0521 & 0.1192 & 0.1285 & 0.1035 & 0.4034 \\
2013 & 0.0586 & 0.0916 & 0.1744 & 0.1785 & 0.5031 \\
2014 & 0.0610 & 0.1079 & 0.2057 & 0.1842 & 0.5588 \\
2015 & 0.0657 & 0.1169 & 0.2317 & 0.2027 & 0.6170 \\
2016 & 0.0705 & 0.1876 & 0.3057 & 0.2135 & 0.7773 \\
2017 & 0.0742 & 0.1797 & 0.3517 & 0.2305 & 0.8360 \\
2018 & 0.0736 & 0.1838 & 0.3951 & 0.2578 & 0.9103 \\
\hline
\end{tabular}


Showed in Table 2, the sustainability of the industrial ecosystem in Shaanxi presents four-stage climbing trend from 2008 to 2018, with the overall trend of gradual migration from a low level to a high level. GDP growth rate has slowed down gradually, whereas SIE has shown a good and steady improvement trend. It indicates that the improvement and implementation of long-term policies in Shaanxi is effective, such as promoting new industrialization, ensuring industrial growth, energy conservation and emission reduction, returning farmland to forests, deepening the coordinated development of three regions and urban-rural areas, etc.

From 2008 to 2009, Shaanxi was indirectly affected by both the Wenchuan earthquake and the international financial crisis, resulting in the following problems emerged: The external market demand shrinking, the export volume declining, the internal earthquake relief, the enterprise capital chain tight, etc. Faced with many unfavorable factors, Shaanxi has implemented the driving strategy with the goal of maintaining growth. Urging banks to lend more credit to enterprises, promoting largescale and infrastructure projects, adopting a number of measures and allocating special funds to help enterprises alleviate their financial difficulties. From 2010 to 2011, the SIE grade of Shaanxi entered a small plateau. Benefiting from the early accumulation of infrastructure construction and economy, development bottlenecks have been eased temporarily, Shaanxi adjusts the policy guidance to the direction of Structural adjustment with consideration of investment expansion. From 2012 to 2015, the level of SIE showed a relatively stable trend of improvement. Shaanxi has experienced a slowdown in industrial growth after golden decade of resource-driven economic growth, and continues to implement the industry-oriented policy placing equal emphasis on restructuring and expand investment and consumption, to increase investment in infrastructure and major projects, and to improve energy conservation and emissions reduction in some key area. From 2016 to 2018, the SIE in Shaanxi has steadily improved from a medium level to comparatively high level. After entering the 13th five-year plan period, the development strategy of Shaanxi focuses on sustainable development with supply-side structural reform, and the emphasis of industrial development shifts from "investment-driven" to "improving quality and efficiency".

\section{CONCLUSIONS AND SUGGESTION}

The sustainability of Shaanxi industrial ecosystem was assessed from both the aspects of economic, social, environmental and energy subsystems and the coupling coordinated development. In the assessment process, a collection of 20 indicators was selected from the four subsystems, according to aforementioned principles of the triple bottom line. The indicator weight was determined by weighting method of CSO. The scientific contributions of the paper are mainly represented in the following two aspects. Firstly, the method of CSO was employed to embody subjectivity with consideration of objectivity, and Coupling coordination degree method was employed to investigate coupling state between the four subsystems. Secondly, the paper conducted SIE of Shaanxi--typical resource exporting region in northwest China, from economic, social, environmental and energy subsystems. The rich evaluation conclusions and policy suggestions can provide beneficial references for SIE of Shaanxi and other energy-dependent regions.

\section{ACKNOWLEDGEMENTS}

This work was supported by the Soft Science Project of Shaanxi Province (2020RZ011).

\section{REFERENCES}

1. Fan, T.S. Research on the Evolution of Regional Low Carbon Industrial Ecosystem Based on LotkaVolterra Model. Science and Technology Management Research. 2014,34(15):219-223.

2. Li, W.W.; Yi, P.T. Assessment of city sustainabilityCoupling coordinated development among economy, society and environment. Journal of Cleaner Production. 2020, 256, 0959-6526.

3. Qin, M.; Liu, Y.; Cheng, C.Z. Comprehensive evaluation of marine industrial ecologization. China Population. Resources and Environment. 2018,28(09):102-111.

4. Zhu, X. The relationship between the population composition of industrial innovation ecosystem and industrial innovation capacity -- an empirical analysis based on vector autoregression (VAR) model. Science and Technology Management Research. 2019,39(21):7-13.

5. Pope, J.; Annandale, D.; Morrison-Saunders, A., Conceptualising sustainability assessment. Impact Assess. Project Appraisal .2004,23 (4), 293-302.

6. Xue, L.M.; Cui, C.Q.; Li, C.M.; Zhu, L.L. HUANG Yu, LIU Bao-kang Normal Cloud model-based approach for regional sustainable power assessment of mineral resources. China Population, Resources and Environment.2017,27(06):67-74.

7. Gong, Q.; Chen, M.; Zhao, X. Sustainable urban development system measurement based on dissipative structure theory, the grey entropy method and coupling theory: a case study in Chengdu, China. Sustainability. 2019, 11 (1), 293.

8. Li, G.; Li, J.P.; Sun, X.L.; Wu, D.S. Research on a Combined Method of Subjective-Objective Weighting Based on the Ordered Information and Intensity Information[J]. Chinese Journal of Management Science, 2017,25(12):179-187.

9. Li, G.; Li, J.P.; Sun, X.L.; Zhao, M. Research on a Combined Method of Subjective-Objective Weighing and the Its Rationality Management Review, 2017,29(12):17-26+61.

10. Sala, S.; Ciuffo, B.; Nijkamp, P. A systemic framework for sustainability assessment. Ecological Economics.2015, 119, 314-325. 
11. Goodland, R., Daly, H., 1996. Environmental sustainability: universal and non-negotiable. Ecol. Appl. 6 (4), 1002-1017. 